\title{
Evangelización e Iglesia
}

José Ignacio González Faus,

Facultad de Teología de Cataluña,

Centro de Reflexión Teológica, San Salvador.

Todo el bien que el Pueblo de Dios puede dar a la familia humana, al tiempo de su peregrinación en la tierra, deriva del hecho de que la Iglesia es sacramento universal de salvación. (Vat. II, GS 45).

De acuerdo a las palabras del Vaticano II que encabezan este artículo, la misión evangelizadora de la Iglesia ("el bien que el pueblo de Dios puede dar a la familia humana") está intimamente ligada al carácter de la Iglesia como sacramento de salvación. No parece exagerado deducir, por tanto, que la "nueva evangelización" que se ha lanzado como programa a raíz de 1992, y de cara al siglo XXI, recibe su novedad del hecho de que la Iglesia actúe plenamente su carácter sacramental, renunciando a anunciar el Evangelio por caminos autoritarios o impositivos.

Esta sencilla consideración brinda ya las dos partes del presente artículo: hay que explicar en qué consiste ese carácier sacramental de la Iglesia. Y después intentaremos mostrar cómo, en el hecho de que la Iglesia consiga actuar su carácter de "signo e instrumento" (LG 1), se juegan sus posibilidades evangelizadoras. De lal manera que las "dos iglesias" que hoy se perciben espontáneamente en nuestra realidad eclcsial (la que intenta vivir el Vaticano II y la iglesia de la "restauración" o involución) son en realidad una iglesia misionera - capaz de dar una Buena Noticia a la familia humana - o una iglesia estéril que fagocila sus propias posibilidades evangelizadoras.

\section{La sacramentalidad de la Iglesia}

La definición de la Iglesia como "sacramento universal de salvación" es mucho menos nueva de lo que puede sugerir su terminología. La terminología 
hizo furor poco antes del Vaticano II, a partir sobre todo de la noción de "sacramento originario" (Ursakrament: Semmelroth) y de la necesidad de explicar la existencia de los siete sacramentos cristianos y su relación con la Iglesia (K. Rahner). Después, esa teología se vio acogida y consagrada por el Vaticano II, como le pasó a buena parte de la teología europea de aquellos antos.

Pero esa terminologla — más allá de su novedad verbal- responde a una estructura de la realidad que encama las relaciones entre 10 -mal llamado"natural y sobrenatural", y que responde a lo que la teología enseña al hablar de la vocación divina del hombre y de la Gracia Se trata de una estructura a la que podriamos calificar como "sacramentalidad anónima", y que retoma la sorprendente visión del encuentro con Dios que ofrece san Mateo en su escena del juicio final (Mt 25, 31ss). Yo mismo he comentado en otro momento esa densidad divina de lo real, valiéndome del célebre cuadro de Miguel Angel sobre la creación de Adán y, especialmente, del conocido póster que reproduce el cncuentro de las dos manos de esa pintura. El mensaje del artista parece ser el siguiente: la mano que se acerca al hombre es la que le hace ser hombre; y esa mano que se acerca, aunque tenga forma humana, resulta ser la mano misma de Dios.

La sacramentalidad "de la mano", que es, a la vez, "signo e instrumento" (LG 1) de Dios, me parece ser la mejor descripción de eso que he llamado sacramentalidad anónima de lo real. La Iglesia se parece entonces al cristiano que ya conoce el capítulo 25 de san Mateo, y trata de actuar en consecuencia, aunque lo que dice ese pasaje evangélico vale también para el no cristiano que lo desconoce. La Iglesia por tanto está en el mundo como la porción en que se actúa esa sacramentalidad anónima de lo real. Y se actúa no sólo porque se ha hocho consciente, sino porque -al concienciarse- se convierte en norma de actuación. Que la Iglesia es sacramento quiere decir que ella se autocomprende como esa mano humana, a través de la cual Dios se acerca al hombre para ayudarlo a ser hombre, para hacerlo "a imagen de Dios" (Gen 1,26$)$ '. Y subrayo que la mano se acerca para ayudar al hombre a ser hombre, no necesariamente para hacerlo cristiano, o prosélito, o para someterlo a la Iglesia. Ślo podrá evangelizar, por tanto, aquél que, más allá de la esclavitud de la Ley, haya hecho la profunda experiencia de la fuerza humanizadora del Evangelio. Y aquí me temo que radica la gran diferencia entre los apóstoles antiguos y algunos de sus sucesores de hoy.

\section{Elementos constitutivos de esa sacramentalidad}

Quisiera mostrar ahora que, entendida así, la noción de la Iglesia como "sacramento de salvación" (que para el Vaticano II parece ser lo mismo que sacramento de comunión: ver LG 1) recoge las tres grandes imágenes o definiciones de la Iglesia que se consideran típicas de la teología paulina: las de 
Pueblo de Dios, Cuerpo de Cristo y Templo (o morada) del Espíritu. Incluso puede estrecharse aún más la correspondencia entre ambos grupos de conceptos, puesto que -como es sabido- los antiguos distinguian tres momentos en la estructura de toda acción sacramental: el signo (sacramentum tantum), el signo con el significado (sacramentum et res) y el significado último (res sacramenti).

Pues bicn, creo que, al designar a la Iglesia como pueblo de Dios estamos aludiendo preferentemente al signo o sacramento: el pueblo es una materia de esta creación, como el agua, o el pan o el vino. Al hablar de la Iglesia como cuerpo de Cristo tenemos ante nosotros el signo y lo significado (sacramentum ef res): la palabra cuerpo tiene aquí un sentido ya más simbólico que, por eso, no se entiende sin Aquél a quien remite (cfr. vg. 1Cor 10,17). Mientras que, al hablar de la Iglesia como templo del Espíitu somos llevados hasta ese Significado último (o res sacramenti) que es el Espíritu de Dios en nosotros (Rom 8, 11): por eso el sustantivo templo se sustituye fácilmente por los de morada o casa, porque el acento recae sobre todo en el dinamismo de lo que se va edificando; y por eso en ouros momentos he traducido lo de morada del Espíritu como: "la Iglesia lugar de la Utopía" (con mayúscula).

Ahora habría que mostrar un poco más estas correspondencias que acabamos de enunciar.

\section{El pueblo de Dios}

En primer lugar, la Iglesia es sacramento por ser "pueblo de Dios", es decir: el misterio de la intima unión de todo el género humano entre sí (pueblo) y con Dios (de Dios), como dice Lumen Gentium l. En contra de lo que ha dicho algún teólogo importante, no hay en esta designación ningún reduccionismo sociológico, sino el hecho de que la materia de los sacramentos es una realidad de este mundo, como lo es el pan de la eucarista, el cual no necesiba ser desfigurado en su realidad de pan, para resultar más sagrado o más signo de Dios.

Es un pueblo, a la vez, convocado por Dios y peregrino en el desiento de esta historia. Y lodavía más: la designación de pueblo de Dios proviene -como es sabido- de la "asamblea" del pueblo de Israel (qahal Yahve) que los Sesenta traducen como ekklesia. Se trata de la asamblea convocada para realizar su misión histórica, no meramente congregada para el culto (en este caso el vocablo usado en el Antiguo Testamento es 'edah, que los Setenta traducen como synagogê). Por tanto: la Iglesia es sacramento en cuanto pueblo convocado por Dios para una tarea historica, no meramente para una sesión cúltica. El Nuevo Testamento ha mantenido también aquí ese traslado de lo cúltico a lo existencial y ese rechazo de la terminología sacral, que le caracteriza en otros momentos (vg. episkopos - supervisor- en lugar de hiereys - sacerdote-) y que ya es conocido. 
Lo que todo eso implica para la vida de la Iglesia lo apuntaremos brevemente en la segunda parte de este trabajo.

\section{El cuerpo de Cristo}

La Iglesia es sacramento además, por ser el cuerpo de Cristo. Esto quiere decir que ella visibiliza la incorporación de toda la realidad a Cristo Cabeza, o la recapitulación de todas las cosas en Cristo. No se dice por tanto que sólo ella estê cristificada, sino al revés: porque todo el universo encuentra su consistencia en Cristo $(\mathrm{Col} 1,17)$ y porque Cristo es cabeza de todo el universo ${ }^{2}$, por eso aparece la Iglesia como cuerpo de Cristo. Es por tanto, como decía Teilhard de Chardin, "la porción conscientemente cristificada de la humanidad", igual que el cuerpo de cada hombre es la porción de mundo en la que se hace visible, que el mundo es "mundo del hombre".

$O$, con otras palabras, que sirven como ejemplos: si tras la resurrección es verdad que lo que se le hace al pobre se le hace a Dios - aunque no se sepa- y ésla es la manera como Dios se nos ha dado, se comprende que haya además alguien en este mundo que proclame eso, y lo fomente, y lo viva. Ese alguien tiene que ser la Iglesia.

$\mathrm{Si}$, tras la resurrección, es verdad que el amor con que amamos al hermano es el Amor mismo de Dios (el Espíritu Santo) derramado en nuestros corazones -aunque los hombres no lo sepan- se comprende que haya alguien que proclame eso y lo fomente, y busque ese amor nuevo. Ese alguien es la comunidad de creyentes.

Si tras la resurrección se convierte en única verdad que la Gloria de Dios es el hombre vivo y la vida del hombre es Dios, ha de haber alguien que custodie esa vida y esa Gloria, de todas las falsificaciones que buscan en lugar alienado tanto la Gloria de Dios como la vida del hombre. Alguien que pracrique ese culto nuevo y cultive esa vida nueva. Ese alguien tiene que ser la comunidad de creyentes...

Pero la palabra cuerpo, por su misma imprecisión, es mucho más polisémica. $Y$ ya en el Nuevo Testamento abarca varios significados, según se la use contraponiéndola a "alma" (el cuerpo como presencia visible de la intimidad de la persona), contraponiéndola a "cabeza" (el cuerpo como instrumento obediente de la mente), o contraponiéndola a "espcso" (designando en este caso al cuerpo amado de la mujer). El primer uso es más propio de las cartas ciertamente paulinas (1Corintios sobre todo): el cuerpo designa aquí esa enorme variedad de funciones unificada por el único principio vital, al que hace visible precisamente en esa comunión milagrosa que impide al cuerpo vivo ser cadáver. La Iglesia en este sentido es Transparencia de Cristo, precisamente porque está animada por el mismo Espíritu del Señor. 
El segundo uso es más propio de las cartas de la cautividad, y el cambio de significado puede estar vinculado al hecho de que ahora "Iglesia" designa a la comunidad universal de creyentes y no a una iglesia local (que era el uso preferido de las cartas paulinas). En cualquier caso, ahora el cuerpo recibe su plenitud de la Cabeza, la cual, a su vez, - y a través del cuerpo- se plenifica en su acción sobre el mundo ( $c f$. Ef 1,23: to pleroma tou ta panta en pasi pleroumenou). La Iglesia es cuerpo de Cristo por la Obediencia a su Cabeza, para manifestar así la acción de Cristo en el mundo.

Finalmente, el tercer significado, como ya es sabido, es propio de la carta a los Efesios (cap. 5) y toma su analogía de la belleza del cuerpo de la mujer, que hace comprensible el amor del esposo. Cristo se prepara una esposa "sin mancha ni arruga" (Ef 5, 27), la ama "como a su propio cuerpo" $(5,28)$, y todo esto es calificado por el autor de la carta como un "gran sacramento" $(5,32)$. La Iglesia se vuelve sacramento por esta especie de Fidelidad conyugal que hace comprensible el amor del Esposo.

\section{El templo del Espíritu}

Finalmente, la Iglesia es sacramento por ser el lugar donde debe manifestarse al mundo la acción del Espíritu que resucitó a Jesús, y quiere mover libremente la historia hacia su incorporación en el "Dios todo en todas las cosas" (1Cor 15, 28).

Sin duda - y precisamente porque en este caso se atiende más a la Realidad Ultima significada por el sacramento- es preciso añadir aquí que (como decían los antiguos) "Deus non tenetur sacramentis" (Dios no está atado a sus sacramentos) y, por eso, el Espíritu sopla donde quiere, y no donde queremos los eclesiásticos. Por eso es legítimo reconocer que de hecho el mundo ha sido más de una vez "sacramento" para la Iglesia (en temas de respeto a la dignidad de la persona o los derechos humanos), y ello a pesar del enorme "pecado del mundo".

Pero, aun con esta necesaria salvedad, la verdad de la Iglesia está en acoger y transparentar a ese Espíritu que resucitó a Jesús y que ha sido derramado sobre la carne de esta historia y no sobre algunas nebulosas evasivas. También hay que reconocer, por ejemplo, que las iglesias de América Latina en los últimos tiempos, han sido muchas veces señal del Espíritu no sólo para los pobres del tercer mundo, sino incluso para muchas gentes del primer mundo: así ocurrió con Medellín, Puebla, con monseñor Romero, el arzobispo Proaño o el cardenal Arns... ${ }^{3}$. Y, para mí personalmente, la incomprensible e indomeñable esperanza de los cristianos de América Latina, empobrecidos, oprimidos, maltratados, difamados, torturados y derrotados por el poder de las tinieblas de "este orden presente", ha sido muchas veces un verdadero sacramento de la presencia de Dios en este sector de la Iglesia. 
De todas estas reflexiones aparece la sacramentalidad (al igual que todas las notas de la Iglesia) como un don que, aunque existe ya, es a la vez una tarea. Hemos de mostrar ahora que, en la acogida de ese don, y en el cumplimiento de esa tarea, se juega para la Iglesia, como decía el Vaticano II, "todo el bien que puede dar a la familia humana". Se juegan por consiguiente sus posibilidades evangelizadoras.

\section{Sacramentalidad de la Iglesia y evangelización}

La Iglesia actual, por brillantes e ingeniosas que sean las fómulas que emplea para disimularlo, nunce ha sido menos misionera que hoy... Es verdad no obstante que aqul tocamos con el dedo el fatal contragolpe del imperialismo clerical de la Iglesia de ayer, en el derrotismo misionero tan sorprendente de la Iglesia de hoy. Durante mucho tiempo, so color de ganar el mundo para Cristo, de "hacer que reine Cristo" como se decía con una ridícula y sacrilega fatuidad, se vivía sobre todo con la preocupación de instaurar de hecho, si no dictaduras de sacristía (aunque se intento siempre que se pudo), al menos una sujeción insidiosa de todas las actividades humanas a una autoridad clerical que se confundía ella misma con el reino de Cristo. La consecuencia que no puede menos de seguirse cuando esta confusión escandalosa se ha visto denunciada y reconocida... está en hacer que caiga en ridleulo el Evangelio. El don de Dios, que habla sido confiado a esta autoridad, y del cual ella había venido a no preocuparse sino para aprovecherse a sí misma, la abandona entonces abandonando por fuerza sus pretensiones abusivas o idólatras. (L. Bouyer, La Iglesia de Dios, pp. 648-649).

La imagen de la Iglesia ha sufrido, a lo largo del siglo XX, una trayectoria curiosa y oscilante. Todavía en los albores del siglo, y una vez pasado el trauma del antimodemismo, R. Guardini se atrevió a profetizar un "despertar de la Iglesia en las almas" que iba a caracterizar al siglo XX. Hacia la mitad de la centuria (1947), de una manera más ambigua, el cardenal Suhard planteaba en una carta pastoral el dilema entre "resurgimiento u ocaso de la Iglesia". Y una oscilación semejante se ha repetido en la segunda mitad del siglo XX: en los momentos del Vaticano II y del pontificado de Juan XXIII la Iglesia alcanzó una de las cotas más altas de credibilidad y significatividad de su larga historia. Mientras que, ya hacia final del siglo, J. B. Metz ha calificado duramente los sentimientos que inspira la Iglesia hoy, como "una caricatura de aquella compasión que se tiene con los moribundos" ${ }^{\prime \prime}$. El proceso que esta situación desata es un círculo vicioso: una superafirmación de la autoridad que, a su vez, impide a la Iglesia ser sacramento de comunión. Ya en 1966, y en una obra que fue declarada por la Catholic Press Association como el libro teológico más importante del afto en Estados Unidos, John McKenzie describió lúcidamente este círculo vicioso: 
La superestimación de la autoridad está intimamente relacionada con la pérdida del prestigio que analizábamos en el capítulo anterior... La supervaloración crea tanto en la jerarquía como en los demás miembros una idea exagerada de su competencia, y al no poder mantenerse a esta altura, se desacredita. Tales exageraciones son especialmente perjudiciales para la autoridad de la Iglesia... Como diría Pablo (Rom 12, 3), la autoridad se sobrestima más de lo debido, alejándose del juicio sobrio. Un falso ideal de la competencia de la autoridad se forma en la mente de los miembros de la Iglesia, y éstos quedan desilusionados al comprobar que la autoridad -como es natural que ocurra-, no llega a realizar esie ideals.

En lo que queda de trabajo, y ciñéndonos a lo ocurrido en la segunda mitad del siglo, quisiéramos mostrar que esa oscilación en la imagen de la Iglesia liene que ver con el concepto de Iglesia como sacramento de salvación. O más exactamente: tiene que ver con que la Iglesia se decida a tomar en serio y a vivir de acuerdo a esa conciencia que ella cobró de sí misma y a esa "definición" que ella misma se dio, o bien que las ignore y las considere irrelevantes para su vida. A mi modo de ver, en esta opción reside una de las razones más profundas de la división que afecta hoy a la Iglesia. Y puede afirmarse que las dos iglesias que hoy coexisten, enfrentadas a veces, se autoidentifican en tomo a ese programa de ser (o no ser) "sacramento de salvación". Ahora vamos a compararlas, y se percibirá claramente por qué sólo una Iglesia que sea sacramento de salvación puede resultar hoy en día evangelizadora, en lugar de meramente impositiva, proselitista o pretenciosa.

Pero, antes de entrar en esla comparación, convendrá lodavía hacer una aclaración previa. La Iglesia es siempre, en algún sentido sacramento de salvación. Lo es incluso en sus peores momentos de conducta histórica porque - como ya escribí en otro momento- pertenece a su esencia el ser "la única institución del globo teráqueo que apela, como razón de su existencia, a esa Victoria Definitiva de la causa de Dios como casusa-delhombre que se ha producido con la resurrección de Jesús. La sola existencia de la Iglesia (aun al margen de su conducta) ya testifica eso... La Iglesia significa así "lo divino de luchar por los derechos humanos" como reza un título de Jon Sobrino. Y eso sólo ya convierte a la Iglesia en señal, sacramento, referencia-a"'s.

Todo esto es muy cierto y viene a constituir, con la jerga clásica, el opus operatum de la sacramentalidad de la Iglesia. Pero la teología clásica enseñaba también que la misma dignidad del sacramento como opus-operatum, exige que se le trate de acuerdo con ella, en el opus operantis, en lugar de dispensar de éste.

Y es aqui donde, a mi modo de ver, se dividen hoy las dos iglesias que ahora vamos a comparar: por un lado la que - por así decir - se contenta con el 
opus operatum de su sacramentalidad (y cuyo opus operantis atiende más a la propia supervivencia que a la propia significación y sacramentalidad). Y por otro lado, la que intenta responder en su actuación a la dignidad de esa Gracia (u opus operatum) de la que ella es sujeto. Es en este último sentido como decimos que sólo una Iglesia-Sacramento puede ser evangelizadora.

Y si aquí pretendemos que sólo una de estas iglesias es fiel al Vaticano II se debe a que el mismo Concilio no sólo dijo que la Iglesia es sacramento, sino que ha sido "enviada por Dios a las gentes para ser sacramento universal de salvación" (AG 1). No es casualidad que este matiz enriquecedor se encuentre precisamente en el Decreto sobre la actividad misionera de la Iglesia Con las palabras subrayadas se corre la noción de sacramento desde la ontología a la práctica y a la conducta (el opus operantis que decfamos hace un momento). La sacramentalidad es así un término que unifica el ser y la misión. La Iglesia no es la salvación (como parecen creer los defensores de la segunda postura que describiremos), sino sólo signo e instrumento de ella. No es la salvación porque ella misma es salvada; y puede ser signo sólo en cuanto salvada.

Pero, aunque no sea la salvación, la Iglesia está obligada a ser sef̂al de ella. La acción del sacramento consta de un doble nivel: manifestar y realizar. Manifestar el amor de Dios a los hombres (GC 45) y la unidad del género humano (LG 1) que encuentra en aquel amor su motivación última y más fuerte. $Y$ realizarla en cuanto es fermento y levadura de transformación del mundo en familia humana y por eso en familia de Dios.

Por definición entonces, la Iglesia sólo va bien si manifiesta y realiza eso. No si su organización funciona perfectamente, o si la prensa habla "bien" de ella o si se entiende hábilmente con los poderes de este mundo, o si consigue grandes plataformas en la opinión pública (tantas veces desaprovechadas despues por lo poco que tienen que decir algunos eclesiásticos). Si la Iglesia fuera una "sociedad de servicios religiosos" todas esas cosas serlan las más importantes y el eclesiocentrismo estaría justificado. Pues la innegable visibilidad de la Iglesia residiría en la impresionante estructura de dicha sociedad (visible "como el Reino de Francia o la República de Venecia" habla escriv Belarmino, y hoy podriamos poner otros ejemplos: visible como el BBV o la CAMPSA...). Pero si la Iglesia es sacramento de salvación en el sentido dicho, se le exige que no tenga nada visible (o institucional) que no sea signo de la gracia. $Y$ al decir que "sea signo" queremos decir que la signifique efectivamente; no que se diga que la significa (vg. del autoritarismo se ha dicho alguna vez que era transparencia de Dios, pero sólo transparenta los Molochs o los ídolos falsos de este mundo).

Por todo esto es por lo que el ser sacramento exige no sólo serlo, sino parecerlo. Esto es lo que antes hemos llamado opus operatun y opus operontis, y ahora va a ser el gozne de nuestra comparación. Para realizar esta comparación vamos a fijamos, más que en la pura materialidad de los textos del 
Vaticano Il (a los que no obstante procuraremos remitir), en aquellos temas y acsitudes en los que, según los comentaristas, parecen polarizarse tanto el espíritu y el significado del Concilio como las fricciones ulteriores. Voy a cxaminar nada menos que 15 puntos o posturas conflictivas. $Y$, de una manera un tanto artificial pero que me resulta pedagógica, las agruparé en tres capítulos que se corresponden con la triple caracterización de la Iglesia comentada en la parte anterior de este trabajo: Pueblo de Dios, Cuerpo de Cristo y Templo del Espíritu (apartados A, B y C de las páginas que siguen).

\section{Las dos iglesias}

En cada uno de los temas que siguen, trataré de describir someramente la que a mi me parece la postura del Vaticano II y, a continuación, (con diferente tipografía) la del sector de Iglesia todavia hostil o reticente al Concilio.

A. Que la Iglesia cs Pueblo de Dios, o pueblo convocado por Dios parece implicar, de acuerdo con el Vaticano II, las actitudes siguientes:

\section{Primacía del Pueblo del Dios}

Precisamente ésta fue una de las definiciones preferidas por el Concilio para declarar el misterio de la Iglesia. Por ella comienza la descripción de la Iglesia que hace la Lumen Gentium. Para ello como ya es sabido, hubo que cambiar el orden de los capítulos 2 y 3 del esquema presentado por la Curia: asi se habló primero del pueblo, como objeto directo de la llamada de Dios, que muestra Su Voluntad de no salvar individualmente. Sólo después, y para ese pueblo, brotan cn la Iglesia unos ministerios. Todo esto parece claro. Pero veamos ahora cómo piensa la otra posura:

La noción de pueblo de Dios es desacreditada como reducción sociológica (acusación bien extraña puesio que explicitamente se nombra a Dios en esta noción). Al hablar de "reducción", se teme probablemente el fuerte acento en la comunión y la igualdad que sugiere la noción de pueblo. Con esta acusación. se desvincula también a la palabra "Iglesia" de su significado etimologico (qahal Yahvé - ekklesia) que alude como ya dijimos a un pueblo en estado de covocación o de asamblea. Y se la convierte en una palabra sin analogías lingülsticas, sobre la que se pueden proyectar, sin demasiado rigor, significados sacros o numinosos.

\section{Superación de la "jerarcologia"}

Jerarcología es la palabra con que Y. Congar calificó críticamente los tratados de Iglesia de los siglos anteriores, siguiendo la otra crítica irónica de J. A. Moehlcr: "Dios creó a la Jerarquía, y ya no tuvo que preocuparse de nada más". Si la Iglesia es antes que nada el pueblo de Dios, y si Dios es antes que 
nada "Comunión Infinita", parece claro que la reflexión sobre la Iglesia no pucde agolarse en un esfuerzo por justificar y magnilicar los poderes de la Jcrarquía. Antes que nada, y como rezaba el título de un libro publicado cuando cl Vaticano II, La Iglesia es una comunión. ¿Qué dice a esto la otra postura?

El término "la Iglesia" sufre un corrimiento de significado, y pasa a significar exclusivamente a la Jerarquía y, con frecuencia, exclusivamente al papa, tal como ya hiciera Egidio Romano ("papa qui potest dici Ecclesia").Esta reducción no es hecha exclusivamente por los de fuera (que a veces hablan vg. de "Estados Unidos" o "Francia" para referise a sus gobernantes), sino cuidadosamente fomensada desde dentro. Así se habla de "amor a la Iglesia". "senrido eclesial", "obediencia a la Iglesia", "seniir con la Iglesia"... y siempre se alude exclusivamente al Vaticano o a la Curia romana. Y esta especie de trampa lingü̈stica es demasiado fácilmente aceprada al interior de la misma Iglesia.

\section{Desidentificación de Dios (o del reino de Dios) y la Iglesia}

La Iglesia no es el reino de Dios, sino sólo su anunciadora y servidora. La Iglesia tampoco es Dios ni dispone de El: sólo pucde preıender transparentarlo para acercar los hombres a El. Ni dcbe pedir que se crea en ella (lo cual sería idolatría), sino sólo que se la acepte como consecuencia de la fe en el Dios de Jesucristo (credo ecclesiam) o que se crea en la acción del Espíritu en toda ella (credo in Spiritum Sanclum in ecclesiam). Este es el tenor de los credos cristianos, y esta humildad de la Iglesia, al volverla a su silio, produjo los mayores acercamientos ccuménicos del Vaticano II.

Desde el otro lado se pide una fe en la Iglesia tal, que prácticamente, sustituya o absorba toda la fe en Dios, con la misma incondicionalidad y totalidad que esa fe implica. No es la fe lo que impone una aceplación amorosa de la Iglesia, sino que ésta es la que impone la fe en Dios. De esse modo la Iglesia se convierte en UNICA y tolal mediación de Dios, identificándose prácticamente con El, y excluyendo todas las otras mediaciones de Dios lla conciencia, la dignidad del ser humano, el clamor del pobre, la misma verdad científica...). $Y$ la prueba de esto es que, si llega a admitirse el conflicto entre alguna de estas otras mediaciones y la Iglesia, siempre, y por principio, habrá de resolverse en favor de ésta última (entendida además como la sola Jerarqula).

\section{Ministerio como servicio ante todo}

La voluntad de Dios sobre la constitución de la Iglesia no debe ser vista como una decisión arbitraria y voluntarista, sino como el respeto de Dios a las leyes de su misma creación, que exige una serie de ministerios para un pueblo en marcha. La voluntad de Dios sobre la Iglesia apunta sobre todo a evitar los pcligros de esa opacidad de lo real, fecundándola con la "nueva creación" y convirtiendo la autoridad en servicio. La famosa "riple potestad" (ensefiar, 
regir, santilicar) no debe ser entendida univocamente con el significado mundano (o incluso "religioso") de esas palabras, sino en analogía con su significado cristológico?.

Pero J. Moltmann dijo en Lovaina, en septiembre de 1990, que el Vaticano era "el último estado totalitario que quedaba en Europa". Y, aunque esta crílica pueda parecer muy dura, nos sirve ahora para hacer gráfica la alternativa a la postura anterior:

Al llamar servicio a la autoridad no se intenta convertir su ejercicio, sino solo cambiar su nombre (porque ha cambiado su finalidad). Se cree sinceramente que, para defender a Dios, le es más útil a la lglesia la innegable eficacia de lo totalitario (cuando logra evadir el clamor de la opinión pública), que la difícil grandeza del Evangelio. Es algo que ya los ultramontanos del siglo pasado (sobre todo J. De Maistre) formularon de mil maneras. Se dice entonces que el Sermón del Monie no vale en absoluto para la I glesia (sino sólo para los individuos) y se concluye que la Jerarquía -puesto que defiende la verdad de Dios - no está obligada a respetar los derechos humanos en el ejercicio de su autoridad.

\section{Colegialidad de obispos y ministerio}

Es de sobra sabido que ésla fue la gran aportación del Vaticano II que, para los situados en esta postura, está todavía por estrenar, y que completaba al Vaticano I, recuperando la figura de Pedro como cabeza del colegio apostólico y no como absolutamente desvinculado de él. El Vaticano II pretendía además que la colegialidad episcopal era sólo un primer paso que había que trasladar a todos los estamentos eclesiales, convirtiendo la colegialidad en principio estructurador de la Iglesia. Y sin que las innegables dificultades de su puesta en práctica menoscabaran la profundidad de las actitudes y opciones fundamentales, que intentan traducir (aun con la imperfección reconocida del término collegium) el principio de que la Iglesia es ante todo una comunión.

Pero ¿cómo se ve la colegialidad desde la otra postura? Cabe decir que la colegialidad no es una estructura de la Iglesia sino un embellecimiento supererrogatorio e innecesario. Como tal, el recurso a ella es absolutamente libre y arbitrario. Pues para la Iglesia se siguen mayores males de la manifestación de diversidades que de no darles beligerancia y acallarlas. En rodo caso, y por razones de opinión pública, puede ir bien hoy urilizar una pantomima de colegialidad, que consiste no en lograr el consenso comunitariamente, sino en provocarlo artificialmente (vg. recabando adhesiones o solicilando peticiones, $y$ premiando las respuestas positivas a estas demandas), o en apelar a la colegialidad sólo cuando se tenga segura la respuesta deseada. Puede ser bueno examinar, en este contexto. qué espacio deja a la Colegialidad (o a qué la reduce) el nuevo Código de Derecho Canónico, pese a ser posserior al Concilio". 


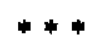

B. Que la Iglesia es Cuerpo de Cristo, o presencia de El, obediencia a El y manifestación de su amor, parece implicar de acuerdo con el Vaticano II, las actitudes siguientes.

\section{Sacramentalidad de la Iglesia}

Ahora nos interesa atender no a los aspectos materiales de ese "signo operante", sino a la opción formal que implica esta caracterización de la Iglesia: el paso del "triunfalismo" al significado y, por tanto, la opción por "invitar a ver" en lugar de dictaminar e imponer. El deseo de una Iglesia que no busca audiencia porque habla triunfalmente de sí misma, sino porque intenta transparentar en su vida la salvación de Dios. El Vaticano I ya había intuido algo de esto al hablar de la Iglesia como signum levatum in nationibus (seftal levantada entre las naciones), pero dando por supuesto que esto acontecía de manera mecánica, y sin pararse a pensar cuántas veces la Iglesia había sido de hecho scandalum levalum in nationibus.

Por el contrario, una de las cosas que más molestaron a la facción curial, en el Voticano II, fue la acusación de triunfalismo que (unida a lo de juridicismo) hicieron algunos obispos, tanto a alguno de los textos presentados, como al talante general de la Iglesia. No es de extrañar pues que la tentación triunfalista rebrote cada vez con más fuerza en esta postura. Esta iglesia habla cada vez más de sl misme y de sus poderes y menos de Dios y de "los gozos y esperanzas y dolores de todos los hombres sobre todo de los más pobres" (GS 1). Rebrotan con fuerza sorprendente esloganes que parecian superados para siempre (y el caso del totus tuus no es el único ejemplo de ello). Si la sociedad civil sólo funciona a base de una manipulación cada vez mayor de los individuos, esta iglesia parece pensar que sólo puede "competir con el mundo" usando las mismas armas que él.

\section{Unidad en la variedad}

Según el Vaticano II, el supremo modelo y principio de unidad de la Iglesia es la comunión trinitaria de Padre, Hijo y Espíritu Santo en un solo Dios (cf. UR 2). De acuerdo con esto, la unidad de la Iglesia como Cuerpo de Cristo implica, ya desde san Pablo, una comunión de pluriformidades, porque ninguna forma humana puede encarnar totalmente el abismo de riqueza del Recapitulador Universal. Por eso el Evangelio es también plural, las eclesiologías del Nuevo Testamento son plurales, pero no enemigas, porque uno solo es El Seffor, y uno solo el Espíritu que da vida a cada cual según su medida.

Para la otra iglesia, el ideal de la unidad de la Iglesia sería una uniformidad 
cada vez mayor que nivelase todas las diferencias. Los más radicales en este campo anhelan incluso la uniformidad del latín. prefiriéndola a la posibilidad de entender la oración de la Iglesia y la Palabra de Dios. La mayoría, sin llegar a este extremo, si piensan que lo que unifica todas las diversidades no es el Espíriru que las hermana sino la Ley que las suprime. Pero en un mundo que se ha vuelto (a la vez y trágicamente) tan plural, tan defensor de las idiosincrasias $y$, por otro lado, tan uniformador, indiscriminadamente uniformador ( $y$ a veces hasta violentamente), una Iglesia uniformada no puede parecer alternativa ni contraste ni, por tanto, sacramento porque (contra lo que dice LG 9) unifica "según la carne" y no según el Espíritu. Mientras que una Iglesia verdaderamente unida en su diversidad, dará al mundo la seffal de salvación que éste necesita.

\section{Importancia de la Iglesia local’}

De una recuperación de la eclesiología del primer Pablo, que no concibe las iglesias locales como "partes" de un todo, ni como iglesias de segunda fila, sino como presencias o formas de la única Iglesia ("la Iglesia de Dios que está en"...), se sigue una concepción de la Iglesia universal como una "Iglesia de iglesias" según la reciente y bella expresión de J. M. Tillard. Todo esto, naturalmente, tiene importantes consecuencias prácticas (de descentralización, etc.) que son las que más asustan a los defensores de la otra posaura, que ahora pasamos a exponer.

Todas las iglesias son sólo (para decirlo con una expresión al uso) "el patio trasero" del Vaticano. El principio de subsidiariedad, del que ya Plo XI dijera que es "un principio muy serio de toda filosofía social que no puede ser cambiado ni quebrantado", y que papas posteriores han presentado como fundamental para regular las relaciones entre la autoridad y las colectividades sociales, ese principio dejaría de regir precisamente en la Iglesia universal y. sobre sodo. en las relaciones entre Roma y las demás iglesias. Los defensores de esta postura argumentan que la iglesia tiene un carácter "sobrenatural" que la distingue de cuanto vincula a las sociedades naturales. Y los defensores de la postura anterior arguyen que ésta otra dafia no sólo al carácter biblico de la Iglesia como koinonía, sino su mismo carácter de "sociedad".

\section{Responsabilidad de los laicos}

Deriva del hecho de que los laicos son propiamente la Iglesia y no el objeto de ella. Para los defensores de esta postura se trata aqui de una de las cosas más necesarias y más salvadoras para la Iglesia del futuro; y no implica de ningún modo una iglesia "paralela" o antijerárquica. Pero sí requiere en los laicos un verdadero sentimiento de pertenencia sin el cual dificilmente puede haber responsabilidad. Y requiere también una aceptación de esa ley psicológica por la 
que el hombre de las sociedades modernas sólo alimenta sentimientos de pertenencia allí donde goza experiencias de participación.

Aun sin formularla asi, los otros consideran como más tranquilizante la opinión de $P$ io $X$ para quien el laico no tenía más derechos en la Iglesia que "obedecer y pagar". En rodo caso, se llega a reconocer una participación mayor a algunos laicos "probados y de confianza", pero sólo como "brazos de la Jerarquía". Y esa confianza en realidad no deriva tanto de su comunión con la fe de la Iglesia, cuanto de su identificación con la política de la institución eclesial.

\section{Identificación parcial entre la iglesia romana y la Iglesia de Jesucristo}

Esta ruptura de la plena identificación tuvo lugar en un pasaje muy concreto que, a pesar de su brevedad, es uno de los textos más importantes del Vaticano Il (LG c. 1, n. 8). Fue aquel que corrigió la frase rotunda del esquema prescntado a aprobación ("esta Iglesia de Cristo es la iglesia católico-romana"), para sustituirla por otra más modesta: "la Iglesia de Cristo subsiste en la iglesia católico-romana".

Por el otro lado se intenta recuperar la identificación plena y exclusiva entre Iglesia de Cristo e iglesia católica. Para ello se argumenta que el subsistit del rexto conciliar debe ser entendido como un est puro y simple. Mediante la identificación plena con la Iglesia de Cristo, la iglesia católica se libera de toda necesidad de reforma y de las amarguras que ella puede comportar. Mediante la identificación exclusiva se niega el carácter de iglesia de Cristo (aun parcial) a todas las demás confesiones cristianas. Esto se concreta por tanto en los dos puntos que ahora van a seguir.

$$
\text { *** }
$$

C. Que la Iglesia es Morada del Espíritu y muestra o señal de su acción en la historia, no sujela a la disposición de los hombres, implica, finalmente, las aclitudes siguientes.

\section{Aceptación de la "Iglesia siempre necesitada de reforma"}

Esta verdad de tan profunda raíz patrística había sido expresamente rechazada por Gregorio XVI en la Mirari vos, con el argumento de que Dios ha dado a la Iglesia toda la santidad y loda la perfección. Sin embargo, la presencia constante de este tema en casi toda la tradición teológica hizo que se fuera abriendo camino cuidadosamente entre los teólogos, para acabar siendo reasumido por el Vaticano II (LG 8, UR 6). Por eso la postura contraria no negará el axioma patrístico, sino que trata de aguarlo o esterilizarlo por los caminos siguientes: 
A lo que pretendía ser una búsqueda de caminos concretos de reforma, se le llama simplemente "experimentos" (no sin algo de razón, pues toda reforma debe ir siendo experimentada y quizás "reformada" a su vez). De este modo, es fácil decir que "ya pasó la época de las experiencias", cuando muchas ni siquiera se hablan estrenado. Se reduce la reforma de la Iglesia a la sola reforma de los individuos de la base (tan absolutamente necesaria como absolutamente insugiciente), y se pretende canonizar las actuales estructuras y funcionamientos de la Iglesia, como si fueran expresión de la santidad misma de Dios. Con lo que, sin querer, la Iglesia resulta totalmente antisacramento, por antisigno o no-significante.

\section{Eclesialidad de otras confesiones cristianas}

Si antes del Concilio el lenguaje conservador hablaba de herejes, y el más progresista de "hermanos separados", el Vaticano II dio un paso audaz e impresionante al calificar a las otras confesiones cristianas como iglesias (UR cap. III, 13, 14, 19...). La importancia de este paso puede entenderse a la luz de dos consideraciones. La primera de carácter espiritual: el mandamiento de que todos scan uno como Jesús y el Padre, es uno de los que más hemos quebrantado todos los seguidores de Jesús. Y otra consideración de carácter más estratégico: sin una suficiente unidad de las iglesias, el cristianismo no puede en modo alguno afrontar el reto del siglo XXI. Todos los eslóganes de nueva evangelización se vuelven "bronce que suena o címbalo que retiñe" (1Cor 13,1) si no se ponen los medios para ello.

Desde la otra optica el ecumenismo es un probleme que trae riesgos $y$, sobre todo, exige humildad y renuncia y desarme y esplritu desinteresado, para atreverse a dar el primer paso. Ante todo esto. "la carne es flaca" y prefiere dormirse y descansar. La unidad se declara entonces como ya existente. Ello implica volver a iratar como herejes a los que están fuera de esa unidad ficticio (y como ellos también son pecadores y pueden ser obstinados, nunca faltará alguna excusa para ello). De aquí se seguirá la acusación de irenismo contra rodo camino de unión que no sea un simple retorno. Los pasos dados, se desandan a continuación. Y así, la Iglesia católica, tras estar presente en la importantísima asamblea de Basilea, volvió a estar prácticamente ausente en su continuación de Seúl. $Y$ así también, una serie de importantes documentos de acuerdo en materias concretas (Lima , Dombes...) han quedado perdidos en algún cajón aguardando reconocimiento oficial. Por otro lado, el trabajo conjunio de opción por los pobres y de lucha por la justicia, que aparecía como un magnífico camino gratuito de ecumenismo, asusta a las iglesias y se va reduciendo a acciones individuales. 


\section{Reconocimiento de carismas y profecia}

Esta actitud deriva del protagonismo dado a los laicos, porque el Espíritu sopla donde quiere (aunque haya de ser discemido siempre) y la jerarquia reconoce que ella no tiene ni la exclusiva ni la disposición del Espíritu (ver GS 43; LG cap. IV, 32-34). Implica pues unas posturas de escucha atenta, de oración prolongada, de aceptación de la crítica, de diálogo y, en ocasiones, de superación paciente y conjunta de las tensiones. $Y$ supone para la Iglesia una forma de vida que es quizá menos cómoda, pero resula mucho más rica y enriquecedora. Pero tampoco se ven así las cosas desde la otra orilla:

Dado el respeto que, a pesar de todo, merecen las palabras "carisma" y "profecla" ya desde los texios fundacionales de la Iglesia, se prefiere no desautorizar esas palabras, sino ponerlas a disposición de los intereses de la institución (en lugar de ponerlas a servicio de sus fines). Se podrá entonces recurrir a estas palabras para justificar una doble medida habitual en los dirigentes de la Iglesia, que suelen tolerar como "respeto al pluralismo" aquellas mismas formas de conducto (o peores) que fustigan y desautorizan como "contrarias a la comunión", cuando circulan en dirección contraria ${ }^{10}$.

\section{Carácter peregrino de la Iglesia}

La conciencia de ser un pueblo que "camina en medio de las tentaciones y de la dificultad" (LG 9) fue otra de las actimdes que, durante el Vaticano II, más acercaron la Iglesia a los hombres y más credibilidad le granjearon. La Iglesia sabía que comparte la común búsqueda del género humano, con servicialidad y sin complejos, porque, sabiéndose regalada con la Palabra de Dios, cree poder ayudar a encontrar soluciones más humanas ( $c f$. GS 40). Pero sabía (y lo confesó expresamente en el Concilio) que no tiene soluciones hechas para muchos problemas humanos, aunque esto no la dispensa en absoluto de buscarlas y de ayudar a encontrarlas.

Desde el otro punto de vista. la Iglesia (entendida ahora prócticamente como la jerarquia), se presenta ante todo como propietaria y depositaria de toda la verdad sobre el hombre, como la única institución que no falla cuando decepcionan todas las empresas humanas. Parece como si lo que constituye su tesoro y le da su autoridad fuera esta posesión de la verdad de las cosas, mucho más que el ser testigo del Amor Manifestado y de la Promesa Salvadora de Dios a los hombres. Por eso no acepla haberse equivocado, no acepta pedir perdón, no acepla rectificar, y cree que - si hiciera alguna vez esto-dañaria irreversiblemente su misión y su credibilidad.

\section{Iglesia de los pobres}

Toda la fuerza de esta opción (propuesta por Juan XXIII antes del Concilio y retomada luego de él y como fruto de él) radica no en el sustantivo pobre, sino 
en la preposición de. Se trata de reconocer quiénes son para la Iglesia sus senores y los vicarios de Cristo, para empezar a caminar en esa dirección. Este camino implica una liberad que la Iglesia todavía no tiene, y una serie de problemas que todavía no están plenamente resueltos y en los que no se puede proceder ingenua o precipitadamente. Pero el solo ponerse en marcha hacia esa meta, le daria a la Iglesia una significatividad para el mundo y le haría prestar al mundo un enorme servicio que la Iglesia sabe que no llevará a cabo sin persecuciones. Pero la realidad de Dios sólo puede ser creíble al mundo si la Iglesia es de los pobres... Aunque como ahora vamos a exponer, hay otro sector de Iglesia que no piensa asi.

El tema de los pobres es probablemente el que más ha influido en las dos iglesias como fruto del Vaticano II. La evidencia de las fuentes cristianas es aquí tan abrumadora, y el pecado de la Iglesia era tan grande, que hoy ninguna de las "dos" iglesias se atreverá a negar la importancia de este tema.

Por eso la diferencia con la postura anterior no está ahora en que se la niegue, pero si en que se la entibia. En lugar de caminar oscuramente hacio una Iglesia DE los pobres (saliendo incluso de Egipto al desierto) se pretende tranquilizar la conciencia mediante una iglesia con atenciones a los pobres. Lo cual es históricamente muy necesario en un mundo tan criminal. Pero es a la vez evangélicamente muy insuficiente. Se buscan excusas acusando a la iglesia de los pobres de ser reduccionisia (y cuando alguien busca excusas nunca le faltarán algunos ejemplos a los que agarrarse). Pero se desconoce así que el mayor reduccionismo del Evangelio y del Ministerio de la Iglesia estaría en que ésia no quisiera ser Iglesia de los pabres.

Al concluir esta comparación quisiera scrialar que no soy yo quien ha elegido los diversos temas comentados: la enumeración de temas procede de un autor y una obra clásicos en la teología aclual". Yo sólo me he permitido suprimir el primero de los puntos de la obra citada ("menor atención a lo jurídico" que, en la otra iglesia, significaría una nueva primacía de lo jurídico) para sustituirlo por el de la Iglesia de los pobres que por eso he puesto en último lugar. Puedo añadir que, si la lista de ternas y actitudes hubiese sido mía, habría elegido algunos otros puntos que me parecen muy importantes, por ejemplo, el de la atención a los "signos de los tiempos", tan caro a Juan XXIII, y que los conservadores desautorizan hoy como si implicase una canonización mecánica de toda novedad, mientras la primera postura sostiene que sólo se trata de "saber leerlos" y que la atención a ellos es sólo respeto a la historia, pero no prejuzga ningún juicio sobre su significado. Y hecha esta última consideración sólo nos 
quedan unas breves observaciones para concluir.

\section{Conclusión: ¿Iglesia sacramento o sociedad de servicios religiosos?}

Hasta cierto punto no debe extrañar la dualidad de iglesias descrita. Ella responde a una dualidad constitutiva de la misma Iglesia, la cual es a la vez escatológica e histórica. Y esta dualidad es tensa. La Iglesia nace de la llegada de la Escatología que tiene lugar en la resurrección de Jesús. Pero nace porque la Escatología no ha llegado aún hasta todo el Cuerpo de Cristo. La tan traida frase despecliva de Loisy ("Jesús anunció el Reino y vino la Iglesia") es perfectamente asumible si se entiende que, porque el reino se hizo presente en Jesucristo, apareció la Iglesia como sacramento de ese reino.

Y codavía otro ejemplo: la Iglesia está también fundada sobre la institución (que representan los Doce) y sobre el carisma de Pablo con quien Dios imumpe más allá de los criterios institucionales, obligando a la institución a reconocerlo, a pesar de que, para los Doce, no fue fácil reconocer la apostolicidad de aquel "abortivo" que no cumplía los requisitos institucionales (recuérdese la resistencia del libro de los Hechos a llamar "apóstol" a Pablo, y no se olvide lo dura que fue la vida de Pablo por esta cuestión). Y el carisma puede ser cuantitativamente minoritario, pero cualitativamente fue tan decisivo para la Iglesia que algunos incluso llamaron a Pablo "fundador del cristianismo".

Todas estas y otras polaridades son intrinsecas a la Iglesia, aunque a la vez debamos reconocer que nuestra Iglesia católica está desde hace cosa de un milenio demasiado petrificada en uno solo de los dos polos, y tiene una particular dispepsia crónica respecto del segundo.

Pero, si las cosas son así, se entiende por qué todas las posibilidades evangelizadoras de la Iglesia están en la primera de las dos imágenes antes descritas. Para creer, los hombres no necesitan más insutuciones, sino señales de otras posibilidades humanas, que son las posibilidades de Dios. Y la misma historia de la Iglesia confurma esta tesis por cuanto, ya en las "dos iglesias" que se dibujaron en el cristianismo naciente (la de Jerusalén y la de Antioquía), ésta segunda fue la verdadera creadora de la misión cristiana. Por eso un proyecto de "nueva evangelización" no podrá ser tal si la Iglesia no incorpora todos los elementos y actitudes que su sacramentalidad le exige. Se limitará a ser un proyecto de reconquista o de neocristiandad, al que yo no veo ningún sentido en el mundo actual.

Sin esta conversión, el verdadero peligro no es que la Iglesia "se quedara vacía" ( $c f$. Mt 23, 38), porque esto mismo resultaría alarmante y obligaría a reaccionar $^{\prime 2}$. El verdadero peligro es que se vaya quedando poblada sólo por fundamentalistas y por obsesos-de-la-seguridad (la cual demasiadas veces es lo contrario de la fe). Y ambos grupos tienden a hacer de su militancia y de su 
fidelidad una patente de corso para descarga de agresividades, lo cual es una ley muy típica de la psicología humana!, pero precisamente la Iglesia debería ensefiar al mundo que el hecho de ser militante no autoriza a ser impositivo ni autoritario, en unos momentos en que la cultura posumodema, harta de tanta agresividad humana, propugna como remedio un desapego egolsta de woda clase de militancia.

Por eso hemos de terminar pidiendo a todos los hombres que sufren no sólo por la Iglesia, sino quizá también a causa de ella, una opción cada vez más seria y profunda por la militancia eclesial. Y una opción creyente -contra spem in spe (Rom 4,18). Pero no porque las perspectivas históricas sean esperanzadoras en estos momentos: cabe pronosticar que en un fumro inmediato Dios sólo nos dará pequeños respiros y no grandes alegrias; porque quizás es todo un milenio de historia del cristianismo lo que debe ser clausurado. Simplemente porque la historia enseña que la Iglesia sólo se ha ido sosteniendo en pie, no gracias al pragmatismo de los que intentaban "salvarla" acomodándose a los criterios de eficacia de este mundo, sino gracias al dolor de los mártires que ella misma produjo. Aquí parece haber algo que enlaza con el misterio de la redención. Pero más allá de eso hay algo que la experiencia hisıórica de la Iglesia parece confirmar. $Y$ como muestra queda ahl esta pregunta con la que concluimos: visto desde hoy ¿quién sirvió más a la Iglesia en el siglo XIX? ¿Los ultramontanos (De Maistre, Bonald, Manning...) o los maltratados por ellos (Newman, Lacordaire, Dupanloup...)?

En mi opinión, la respuesta no ofrece duda. Y la misma cuestión puede plantearse para la primera milad de este siglo (Congar, De Lubac, Rahner... o sus hoy ya desconocidos inquisidores), y para otros muchos siglos de la historia's.

\section{Notas}

1. Ver lodo el n. 39 de GS.

2. Cf. Ef 1.23 en la versión griega, no en la Vulgaca.

3. Sobre la irradiación de monseñor Romero quiero reproducir lo que él mismo anoto en su diario. al recibir de las iglesias suecas el Premio de la Paz de 1980: “Me dijo (el portador) que al pedir el consentimiento del ministerio de culto se mostró muy complacido y dijo que 'para Monseñor Romero y para la diócesis de San Salvador, todo lo que quieran de Suecia'". (Diario, Arzobispado de San Salvador, 1990, p. 449).

4. Esta cita y las dos anteriores se encuentran en el estudio de H. Fries, "Cambios en la imagen de la lglesia", en Mysterium Salutis $N, 1$, pp. 284, 287 y 290.

5. La autoridad en la /glesia, Bilbao 1968, pp. 128-129.

6. "La Iglesia lugar de la utopía", en AA. VV. Grandes injusticias de hoy, Madrid $1987,147-148$.

7. "...Su autoridad y sacra potestad de la que usan únicamense para edificar a su grey 
en la verdad y en la santidad, teniendo en cuenta que el mayor ha de hacerse como el menor y el que ocupa el primer puesto como el servidor (Le 22, 26-27)" (LG 27). La palabra subrayada ser̃ala exactamente lo que todo un sector de Iglesia echa hoy de menos en gran parte de la jerarquía y en Roma: porque la verdad y la santidad son cosas que no pueden ser fruto del poder y la imposición, sino sólo de la convicción y la libertad. Por eso lo único "sacro" en el cristianismo es el anor (cf. 1Jn 4,8), y todo lo que no provenga de ahí será sólo una potestad pseudosacralizada e idolátrice

8. En este sentido debemos reconocer que hoy resultan proféticas aquellas palabras de O. Cullmann poco después del Concilio: "Nos encontramos ante una siujación paradójica: en este capítulo [3 de LG] el dogma del primado papal se menciona más veces que en el texto del Vaticano I de 1870. Con una insistencia que cansa, más bien cómica, cada declaración sobre la colegialidad de los obispos se encuentra doblada con la advertencia de que esta colegialidad no atenta para nada a la primacía papal... En realidad sólo se da aqul una yuxtaposición de dos tesis y no una síntesis propiamente dicha". (Vrai et faux oecumenisme, Neuchâtel 1971, 17-18).

9. "Esta Iglesia de Cristo está verdaderamente presente en todas las legítimas reuniones locales de los fieles que, unidos a sus pastores, reciben también en el Nuevo Testamento el nombre de iglesias": (LG 26).

10. La seriedad de esta afirmación obliga a poner ejemplos concrecos, aunque ello pueda molestar más a algunos. Son bastantes los eclesiásticos que, cuando los ricos torturan y asesinan a los pobres se han limitado a llamar piadosamente a la "reconciliación", y cuando los pobres protestan desesperadamente contra los ricos, han condenado severamente el "comunismo". En 1986, los obispos argentinos amenazaban con la excomunión a los diputados y senadores que no se desolidarizaran de la ley del divorcio; pero antes no hubo ni una amenaza de excomunión contra worturadores, masacradores, desaparecedores y asesinos militares que además, en el caso de Argentina, eran menos arónimos que en ringún sitio: también aquí se pretendió arreglar el asunto con llamadas abstractas a la reconciliación. ( $Y$ cito este ejemplo porque aparece ya en el libro de R. Dumont, L'Eglise demanielee, Bruselas 1990, pp. 41-44). O bien se califica de "profética" a la Primera Instrucción sobre la teología de la liberación que fue precisamente aplaudida por Pinochet y por Wall Street (profetas ellos también a lo que se ve), sin aceptar la sospecha de que esos aplausos indican que la Instrucción era, por lo menos, descontextuada. Y un último ejemplo: cuando el doloroso conflicto de monseñor Romero y "sus propios hermanos de báculo y de mesa" (P. Casaldáliga) siempre fue Romero el reprendido y el conminado a no romper la unidad (y de estas reprensiones, del dolor y las reflexiones que le producían, quedan huellas frecuentes en su diario). Pero cuando otro conflicto dividió a las carmelitas que habían aceptado la reforma impulsada por Pablo VI, y las que se habían resistido a ella con uñas y dientes, se resolvió la división en favor de éstas últimas, con el argumento de que "la Iglesia respeta la pluralidad"...

Son demasiados los casos en que muchos eclesiásticos que parecen colar mosquitos insignificantes de diezmos y comino y tragarse camellos impresionantes de injusticia y falta de misericordia, deberían recordar aquellas palabras de Jesús: haec oportuil facere et illa non omiflere (Mt 23, 23).

Y aún cabe añadir aquí la práctica tan común de desautorizar las causas de los 
profetas por los defectos humanos de éstos, sobre to cual escribió ya hace años J McKenzie, hablando de Savonarola: "no comprendo exactamente por que estos defectos deben convertir a un profeta en ilegítimo, cuando las mismas limitaciones no privan a los jerarcas de la Iglesia de su jurisdicción" (op. cir. 181).

11. Ver el artéculo citado de H. Fries, en Mysterium Salutis IV, 1, 287-288.

12. Y hago esta afirmación a pesar de que yo mismo he escrito en otro momento que "es pecado úpico de la Iglesia preferir que las cosas mueran como están a que renazcan como podrían (y deberían) estar" (Proyecio de hermano. Visión creyente del hombre, Santander 1987, p. 301).

13. Durante la redacción de este arúculo, se me pidio una lectura del Documento preparatorio de Santo Domingo. Ateniéndome a lo leído debo decir que me ha parecido un ejemplo doloroso de un texto nada significante para una iglesia no sacramental. Da la sensación de que su objetivo no luese evangelizar sino justificar, no cambiar sino conservar, no anunciar una buena noticia sino defender una mala realidad; y. más que consolar a los pobres, ranquilizar a los ricos. Pero es inevitable preguntarse si, para un objetivo como ese, se justifica el enome gasto y esfuerzo de una asamblea como la del CELAM. ¡Ojalé Dios haga más que nosotros los hombres! 